\title{
ANALYSIS OF BUS DRIVERS REACTION TO SIMULATED TRAFFIC COLLISION SITUATIONS - EYE-TRACKING STUDIES
}

\section{ALICJA BORTKIEWICZ ${ }^{1}$, ELŻBIETA GADZICKA ${ }^{1}$, JADWIGA SIEDLECKA ${ }^{1}$, MARCIN KOSOBUDZKII ${ }^{1}$, MARTA DANIA ${ }^{1}$, WIESŁAW SZYMCZAK ${ }^{2}$, ZBIGNIEW JÓŹWIAK ${ }^{1}$, AGATA SZYJKOWSKA ${ }^{1}$, PIOTR VIEBIG ${ }^{1}$, ALICJA PAS-WYROŚLAK², TERESA MAKOWIEC-DĄBROWSKA ${ }^{1}$, BRONISŁAW KAPITANIAK ${ }^{1}$, and JEFFREY S. HICKMAN ${ }^{4}$}

\author{
${ }^{1}$ Nofer Institute of Occupational Medicine, Łódź, Poland \\ Department of Work Physiology and Ergonomics \\ ${ }^{2}$ University of Lodz, Lódź, Poland \\ Department of Psychological Research Methodology and Statistics \\ ${ }^{3}$ Nofer Institute of Occupational Medicine, Łódź, Poland \\ Outpatient Clinic of Occupational Diseases \\ ${ }^{4}$ Virginia Tech Transportation Institute, Blacksburg, USA
}

\begin{abstract}
Objectives: The aim of the study was to establish whether the driver's visual strategy may influence a driver's behavior to avoid a crash in a high-risk situation. Any published papers on drivers' visual strategies just before a crash were not found. Material and Methods: Tests were performed using a high-tech driving bus simulator. Participants comprised 45 men drivers, aged $43.5 \pm 7.9$ years old, seniority as a bus driver of $13.3 \pm 8.6$ years. The tests were preceded by medical examinations: general, neurological and ophthalmological. Each participant drove the same city route for approximately $40 \mathrm{~min}$ (entire route - ER). In the final phase, a collision situation was simulated (a phantom car blocked the participant's right of way). Driver's visual strategy was analyzed using the FaceLab device with 2 cameras during ER and just before collision. The field-of-view covered by camera 1 was divided into 8 regions, by camera 2 into 10 regions. The distribution of gazes in regions was a criterion of visual strategy. Results: Thirty-five drivers completed the simulated driving test, 14 escaped the collision, 21 crashed. These groups differed only in resting systolic blood pressure before the test. The analysis of covariance, after adjusting to this factor, indicated that during the ER visual strategy recorded by camera 1 did not differ between groups, in camera 2 the drivers in the crash group fixed their gaze more frequently $(p=0.049)$ in region 3 (close part of the road in front of the windshield). Just before the collision drivers who escaped the collision fixed their gaze significantly more often in region 6 (left side of the road) in camera 1 and in region 6 (in front of the windshield,) and region 10 (right side) in camera 2. Conclusions: The visual strategy has an impact on the road safety. The analysis of visual strategies may be a useful tool for the training of drivers. Int J Occup Med Environ Health. 2019;32(2):161-74
\end{abstract}

Key words:

road safety, driver, eye-tracking, visual strategy, accidents, driving simulator

\footnotetext{
Funding: this study was supported by The National Center for Research and Development (project No. uda-poig.01.03.01-10-085/09 entitled "Integrated system for monitoring the psychical and physical condition of road vehicle drivers to minimize hazards in road traffic," project manager: Prof. Alicja Bortkiewicz and project No. PBS3/B9/29/2015 the innovative economy programme: priority 1. Research and development of modern technologies activity (No. uda-poig.01.03.01-10-085/09) and project PBS3/B9/29/2015, entitled: "Detector of early signs of fatigue as a part of improving the safety driving (Det)," project manager: Prof. Alicja Bortkiewicz). Received: November 15, 2017. Accepted: May 14, 2018.

Corresponding author: Alicja Bortkiewicz, Nofer Institute of Occupational Medicine, Department of Work Physiology and Ergonomics, św. Teresy 8, 91-348 Łódź, Poland (e-mail: alab@imp.lodz.pl).
} 


\section{INTRODUCTION}

Several factors have been shown to increase the risk of crashes, including road conditions due to heavy traffic, adverse weather conditions, road geometry, vehicle-related defects, and unsafe behavior by drivers and/or pedestrians/pedalcyclists [1,2]. The group of people who most frequently use the roadway, and are therefore significantly exposed to traffic crashes, includes workers employed as drivers of motor vehicles (or professional drivers). Longdistance truck driving is one of the most dangerous occupations, saddled with the highest risk of crash. According to the Federal Motor Carrier Safety Administration, truck drivers in the United States are involved in about $10 \%$ of all fatal crashes [3].

Data from the police reports on traffic crashes in Poland in 2014 shows that unsafe behavior (drivers and/or pedestrians/pedalcyclists) was the most common cause of crashes (91\% of the cases) whereas another $9 \%$ of crashes were attributed to vehicle-related defects and adverse weather conditions [4]. The latest available statistics in Poland indicated that bus drivers caused 347 (or 1.1\% of the total) crashes in 2013. These statistics are not limited to Poland. Hassan et al. found that "driving behavior," especially in not respecting other road users, was the primary cause of crashes in the United Arab Emirates [5]. Data from the U.S. also indicates that unsafe driver's behavior is the primary contributing factor in crashes [6-8].

Various studies have found that a driver's visual capacity is a major component of safe driving [6,8]. In a study of 55-90-year-old drivers, Owsley found an increased crash risk at twilight, which was attributable to cognitive impairment but also impaired sensory capacity (i.e., lower visual acuity, deficient twilight vision, or limited field-ofview) [9]. Hazard perception tests (HPT) have been developed in a variety of formats, including those utilizing still images [10-12] or simulated plan views of potentially hazardous scenarios [13], dynamic video sequences [14-16] and simulations [13].
Scialfa et al. has developed a HPT that distinguishes groups of drivers with different risk behavior (young/old) $[15,17]$. This test consists in presenting short video scenes to observers who should indicate the presence of a traffic conflict that would lead to a collision between the "camera" vehicle and that of another road user. The test allows for calculation of the reaction time, miss rate, and false alarm rate.

The fundamental principles of the construction of this test were reported by Wetton et al., who evaluated this test with a sample of novice and experienced drivers [18-20]. A similar concept of the simulated driving assessment (SDA) was evaluated by McDonald et al. [21]. Although the authors concluded the SDA was relevant to assess the quality of driving, this kind of test was evaluated using subjective methods, not an objective analysis of eyemovements using eye-tracking technologies.

It is generally recognized that visual attention errors are responsible for a large proportion of traffic crashes [2225]. Chapman and Underwood [26] showed the driver's gaze fixation on straight stretches of a road may be described as focusing on the target point, with rare glances to the road signs and markers of the edge of the road. It is expected that a dangerous event will involve a significant increase in the duration of the fixation [26]. Several studies (Kapitaniak et al. 2015 [7] for a review) have shown that eye-tracking is currently the method of choice for studies assessing cognitive strategies (in particular, visual strategy) [7]. Currently available techniques allow for the use of this method in simulated and real-world driving without the need for wearables. The results enable a quantitative assessment of the parameters of the visual strategy and make it possible to compare the strategies in different experimental conditions. For example, the number of fixations, the average time of fixation, and the zone of exploration of the functional field-of-view are variables most commonly used in the assessment of the visual strategy $[7,27]$. 
Taylor et al. have found the use of appropriate on-road glance-monitoring technologies has greatly enhanced our understanding of drivers' visual behavior [28]. This knowledge has paved the way for significant improvements in road user safety. Studies using eye-tracking during simulated driving have been concerned primarily with differences in visual strategies by age [26,29-31], time of a day (day vs. night) [31-33] or driver steering responses [34-38].

Examination of the visual reaction (eye-tracking) in the case of drivers during dangerous situations, such as crashes or near-crashes is difficult because it is impossible to predict when such a situation will occur. Currently, driving simulators allow for accurate simulations of real-world driving conditions. Thus, this seems to be the optimal method for assessing a driver's behavior in dangerous situations on the road [39].

The use of the driving simulator allows for the driver to experience a dangerous situation which is very close to reality, and recording the driver's visual strategy before and during this situation. The results of simulation studies confirm the driver's behavior in a driving simulator is very similar to real-world driving [7]. The aim of the study was to test the hypothesis that the driver's visual strategy may have influence on the possibility of avoiding collision during a high-risk situation.

In the review of the literature, the authors were unable to find published reports on drivers' visual strategies during a crash.

\section{MATERIAL AND METHODS}

\section{Participants}

The group of participants was comprised of 45 professional male city bus drivers. The average age of participants was $43.5 \pm 7.9$ years old. The overall duration of employment was $24.5 \pm 9$ years, out of which $13.3 \pm 8.6$ years was as a bus driver. Participants were volunteers from a municipal bus company, with current medical examination to qualify for professional driving.

\section{Apparatus}

The driving simulator used in the current study was built by ETC-PZL Aerospace Industries Co. Ltd., Poland. It enables full simulation of a bus driven in all kinds of different terrains, roads and weather conditions, car and pedestrian traffic flows, behavior of other road users, and vehicle defects. The main feature is a replication of a bus cabin (e.g., AUTOSAN LIDER 1010T) (Figure 1).

The cab is mounted on a mobile platform with 6 degrees of freedom, simulating the movements of the bus under real-world conditions.

The simulator has a visualization system equipped with a screen that has a $180^{\circ}$ horizontal field-of-view and $40^{\circ}$ vertically $(1024 \times 768$ pixel image resolution single channel graphic projectors). In addition, the cabin has a screen that simulates images seen in the rear-view mirrors (visualization on mirror-mimicking monitors).

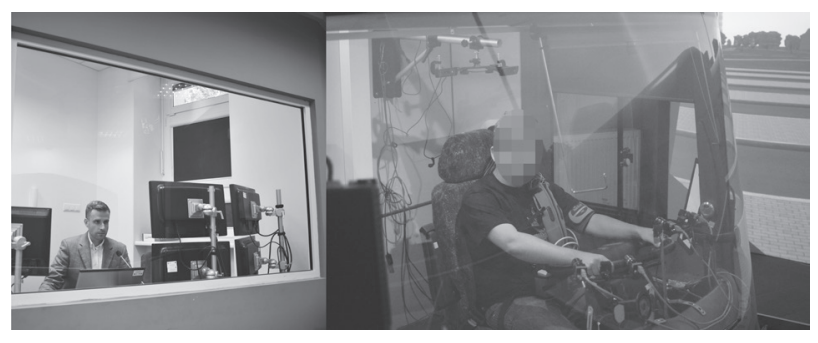

Figure 1. The cabin of the AUTOSAN LIDER 1010T bus simulator and a view of the operator station

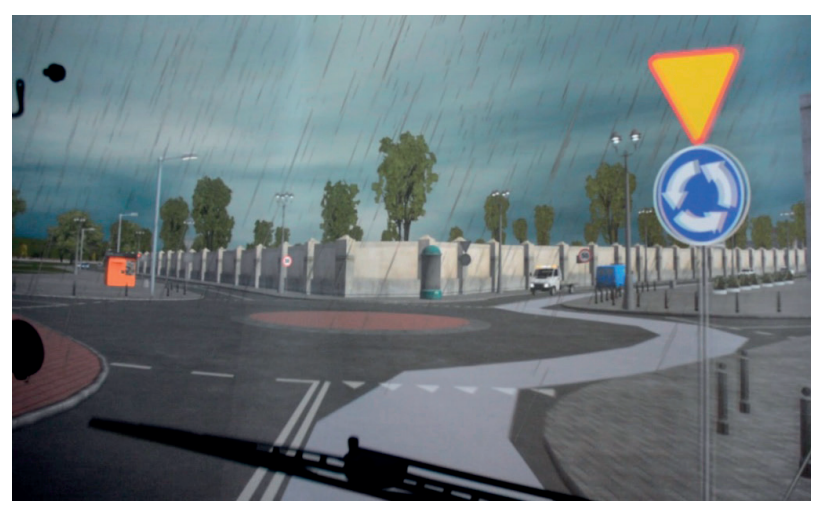

Figure 2. Grey path indicated a proper route to drive - a view of a city route from the cabin of a bus simulator 


\section{The protocol of the study}

Ethics

The testing procedure was approved by the Regional Bioethics Commission of the Nofer Institute of Occupational Medicine in Łódź. The participants were informed about the purpose of the study and procedures of the test and gave their written consent to participate in the study. Participants were compensated according to rules applied in the Nofer Institute of Occupational Medicine for studies on volunteers.

\section{Medical examinations}

The tests on the bus simulator were preceded by general medical, neurological, and ophthalmological examinations. Results of neurological examinations are published elsewhere [40]. Participants underwent a general medical examination, including anamnesis with blood pressure measurement and a detailed interview regarding identified diseases; lifestyle and dietary habits; physical activity; intake of drugs, coffee, tea, alcohol, and smoking status.

The condition of the nervous system was assessed on the basis of a clinical neurological examination, including questions regarding diagnosed diseases and subjective ailments related to the nervous system. In the participant-indicated headaches, the classification and criteria of the International Headache Society was applied [41]. During the physical examination, the state of the participants' intracranial nerves, locomotor, and sensory system and coordination of movements were assessed.

Ophthalmological examinations included: evaluation of symptoms in the eye were conducted according to the prepared questionnaire and baseline eye examination. Questions related to vision, applied correction or spectacle lens, past injuries and inflammations of the eye or head, surgeries, ophthalmic diseases, and ophthalmologic drug use. In addition, participants were evaluated for any symptoms in the eye (e.g., eye pain, stinging), photophobia, redness, burning, itching, sand, dryness, tearing, increased mucus, limitation in the movement of the eyelids, loss of focus, haze vision/sight/seeing in the day, vision disorder in the evening/at night. The symptoms were rated on a 4-point scale ( 0 - none and 4 - severe).

The baseline eye examination involved the assessment of visual characteristics, such as visual acuity, field-of-vision, color vision, stereoscopic vision, twilight vision, sensitivity to glare and contrast sensitivity. The baseline examination was expanded to include additional tests to evaluate the contrast in photopic conditions and night vision. In addition, tests were conducted assessing the tear film on the driver's eyes: the Schirmer test evaluating the aqueous portion of the tear film and the test evaluating tear film stability - the Tear Stability Analysis System (TSAS).

The medical examinations were performed on a non-work day and the simulator test took place on a separate nonwork day. The participants were informed that they should take a normal sleep and do not drink coffee or alcohol before the simulator test.

The medical examinations and simulator test were performed after a normal night of rest. The sleep duration was evaluated on the basis of the self-report information received from participants. The test was always performed at the same time, during the morning hours, to avoid the influence of circadian cycles of various functions of the body on the test result.

On the day of the simulator test, participants completed a short questionnaire to elicit information on the length of night sleep and subjective feeling of fatigue. They had also a second test of visual acuity, contrast examination in daylight, and examination assessing the tear film: Schirmer test and TSAS. After completing their simulator drive, participants completed all ophthalmic examinations described above, including: evaluation of symptoms and eye tests of visual functions (e.g., visual acuity, stereoscopy, field-of-vision, color vision, twilight vision, sensitivity to glare, contrast in different lighting conditions: sensitivity 
to contrast, night vision, and tests assessing the tear film (Schirmer test and TSAS).

\section{Simulator tests}

Prior to the actual simulator drive, participants were instructed about the experiment procedure and were allowed to become acquainted with the bus simulator. This was followed by a 10-min orientation drive to familiarize the driver with how the simulator operated and the use of the vehicle controls. During the actual test each participant drove the same city route developed on the basis of realistic timetables. The route included 10 four-way crossings, 11 T crossings, 8 left branches, 8 right branches, 4 roundabouts, 40 pedestrian crosswalks, and 23 bus stops.

The participants were instructed to follow a marked route (gray trail as shown in Figure 2) obey all traffic regulations, and stop at all the bus stops.

Each simulator test lasted approximately $40 \mathrm{~min}$, the exact duration of the test was dependent on the how fast each participant drove. At the end of the test, an imminent collision scenario was presented to the participant: a driver in a phantom car coming from a subordinate road failed to yield the right of way as the participant entered a roundabout. The time from the moment the participant entered the roundabout until the phantom car blocked the participant's right of way (initial time to collision - TTC) was about $20 \mathrm{~s}$. It was assumed that TTC means reaction time.

The collision situation was so arranged that the only defensive action of the driver was braking.

The participant's visual strategy was assessed over the entire simulated drive. However, in the 20 -s period during the imminent collision scenarios, the speed of bus prior to the collision and the reaction time between the start of the phantom car and the beginning of braking action were also recorded.

Participant's visual strategy was captured using the methodology described by Rayner [42] and adapted by the authors in the current study. The participant's detection field-of-vision was about $120^{\circ}$.

The calibration process was followed by a procedure designed to synchronize the FaceLab, the Eye Works Record, CAPTIV systems, and the bus simulator. Programs for the oculographic analysis required the calibration before each test. In the calibration process the following was included: a set of cameras for eye movement recording infrared pod, 2 cameras and computer programs: FaceLab, Eye Works Record, CAPTIV, and the simulator software (Figure 3).

The CAPTIV system was the key element for the oculographic examination and assessment of driver behavior during the simulated driving test. This software allowed synchronization of data from the simulator (such as speed, braking, using the accelerator pedal, steering wheel, etc.) with data supplied by the FaceLab and the Eye Works Record systems. By combining this data, it was possible to obtain video recording data synchronized with driver gaze and simulator data. The FaceLab allowed us to perform the gaze tracking, which was estimated where a participant was looking.

We adopted the distribution of the gaze in a particular region as a criterion of visual strategy. The FaceLab records the gaze as the eye movements stop over $17 \mathrm{~ms}$. This choice allows for a meaningful analysis even for the very short periods of time. The measurement of the eye gaze

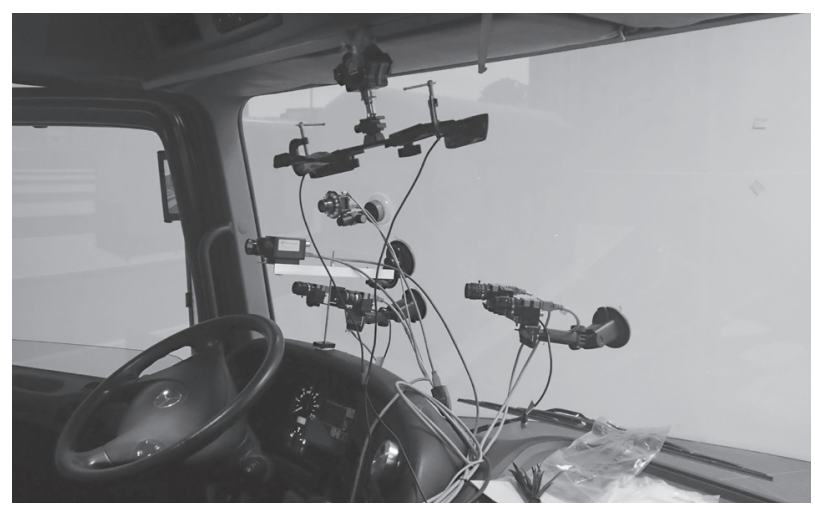

Figure 3. FaceLab device mounted inside the cabin of a simulator 


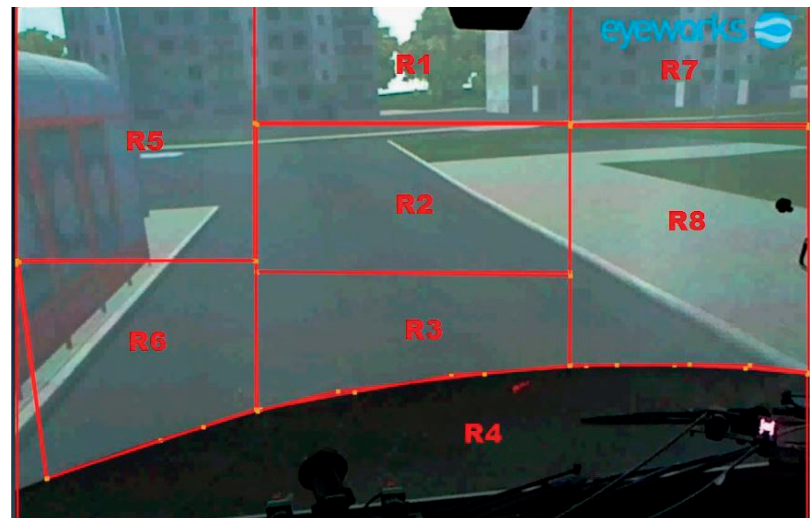

Figure 4. Image from scene camera 1 including the 8 regions received during the simulator drive

direction allows the FaceLab to accurately assess the visual behavior of the driver.

The image displayed from 2 scene cameras covered the part of the visual field most important for driving, including the direct view through the windshield, the right side mirrors, and the upper part of dashboard. For the technical reasons of the organization of the bus cockpit, it was impossible to cover the entire field and therefore the gaze percentage registered is less than $100 \%$. The image displayed from the scene cameras was divided by the Eye Works Analyze software into several smaller areas or "regions." The choice of regions was dictated by the interest of each region in the observation of the functional visual field. The image from the camera 1 represented the view in front of the driver (Figure 4), which was divided into 8 regions.

Thus, 3 regions represent the central vision, 2 lateral visions of 2 sides (left and right), and 1 region's vision on the dashboard. The image from the camera 2 represented the view to the right side of the driver and was partitioned into 10 regions (Figure 5). The functional visual field through the windshield was divided into 3 parts: 1 central region and 2 side regions (each was divided into the upper and lower region of the field). Two other regions concerned both side mirrors and the other 2 parts of the visual field were portioned above and below the windshield (Figure 5).

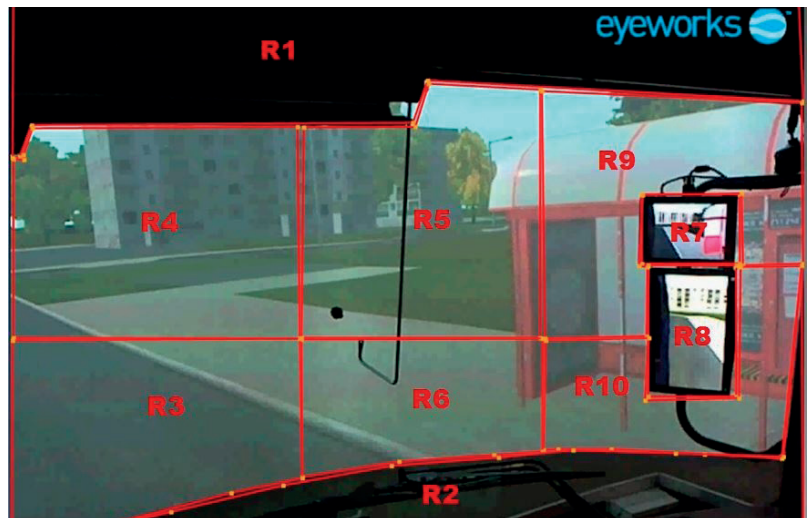

Figure 5. Image from scene camera 2 including the 10 regions received during the simulator drive

\section{Statistical analysis}

The authors assumed that additional factors could potentially affect the different visual strategies of drivers. This was tested with an analysis of covariance (two-way analysis of variance with repeated observations with 1 factor - the camera) with an additional variable as covariance.

The following methods were used in the statistical analysis. The $\chi^{2}$ test of independence or Fisher's exact test (depending on the expected frequencies in contingency table cells) for comparing the frequency of the incidence of smoking and drinking strong alcohol. The one-way analysis of variance for comparing the expected values of continuous variables (age, seniority, BMI, alcohol consumption in $\mathrm{ml} / \mathrm{month}$, number of hours of sleep per a working day, on a day off, heart rate, systolic and diastolic blood pressure). The two-way analysis of variance with repeated measures on 1 factor (group - crash/no-crash, gaze fixation) from the entire route (cameras 1 and 2), and data from $20 \mathrm{~s}$ before the collision (camera 1). The two-way analysis of covariance with repeated observations on 1 factor with systolic blood pressure as a covariate using data from $20 \mathrm{~s}$ before the collision (for camera 2), supplemented by an assessment of the simple effects in individual regions between the 2 groups of drivers. The authors used Bonferroni correction for multiple comparisons. 
All statistical tests used a level of significance $\alpha=0.05$. Calculations were performed using SPSS version 22 and Stata version 13.

\section{RESULTS}

\section{Characteristics of the subjects}

Out of the 45 participants who completed the initial examination, 35 (77\%) completed the simulated bus driving test. The remaining 10 participants did not complete the driving test (8 participants experienced symptoms of simulator sickness and in 2 cases the test was interrupted due to a driving simulator defect). Out of the participants who completed the simulated driving test, 14 drivers (40\%) escaped the collision and 21 drivers $(60 \%)$ crashed. The Table 1 shows the characteristics of the crash vs. no-crash group.
Only 5 drivers $(11 \%)$ were of normal weight $(\mathrm{BMI} \leq 25)$, 23 individuals $(50 \%)$ were overweight $(25<\mathrm{BMI}<30)$, and 18 participants $(39 \%)$ were obese $(\mathrm{BMI}>30)$. The no-crash group differed from the crash group mainly in the proportion of smokers. The percentage of smokers in the crash group was higher than in the no-crash group, but due to the small overall number of smokers ( $\mathrm{N}=2$ vs. $\mathrm{N}=9$ ), the difference was not statistically significant.

The groups did not differ significantly in age, length of employment (seniority), BMI, alcohol consumption, and duration of sleep. In medical examination, there were no significant differences in mean values of heart rate and diastolic blood pressure. In contrast, the mean value of systolic blood pressure was significantly higher in the crash group. Before test all participants declared that they felt fresh. Details are shown in the Table 1.

Table 1. Characteristics of the study group in tests of the driver's visual strategy and its influence for a driver's behavior to avoid a crash in a high-risk situation

\begin{tabular}{|c|c|c|c|c|}
\hline \multirow[b]{2}{*}{ Variable } & \multicolumn{3}{|c|}{ Subjects } & \multirow[b]{2}{*}{$\mathrm{p}(0$ vs. 1$)$} \\
\hline & $\begin{array}{c}\text { total } \\
(\mathrm{N}=35)\end{array}$ & $\begin{array}{c}\text { no-crash }(0) \\
(\mathrm{N}=14)\end{array}$ & $\begin{array}{l}\operatorname{crash}(1) \\
(\mathrm{N}=21)\end{array}$ & \\
\hline Age [years] $(\mathrm{M} \pm \mathrm{SD}$ (range) $)$ & $44.4 \pm 6.7(32-60)$ & $44.8 \pm 6.8(32-60)$ & $44.2 \pm 6.8(35-59)$ & 0.80 \\
\hline Seniority [years] (M \pm SD (range)) & $22.6 \pm 7.2(10-42)$ & $23.1 \pm 7.8(10-42)$ & $22.3 \pm 7(10-40)$ & 0.77 \\
\hline Seniority as a driver [years] $(\mathrm{M} \pm \mathrm{SD}$ (range) $)$ & $13.3 \pm 8.5(2-33)$ & $14.9 \pm 8.6(4-33)$ & $11.4 \pm 8.3(2-26)$ & 0.17 \\
\hline $\mathrm{BMI}\left[\mathrm{kg} / \mathrm{m}^{2}\right](\mathrm{M} \pm \mathrm{SD})$ & $28.8 \pm 3.9$ & $28.8 \pm 3.8$ & $28.8 \pm 4$ & 0.97 \\
\hline Smokers $[\mathrm{n}(\%)]$ & $11(35)$ & $2(14.3)$ & $9(43)$ & 0.14 \\
\hline $\begin{array}{l}\text { Subjects drinking strong alcoholic drinks } \\
\text { at least once a month [n }(\%)]\end{array}$ & $17(49)$ & $8(57)$ & $9(42)$ & 0.45 \\
\hline Alcohol intake [ml/month] $]^{*}(\mathrm{M} \pm \mathrm{SD})$ & $260.8 \pm 350$ & $204.4 \pm 174.9$ & $298.5 \pm 369.7$ & 0.38 \\
\hline \multicolumn{5}{|l|}{ Sleep $[\mathrm{h}](\mathrm{M} \pm \mathrm{SD})$} \\
\hline night before workday & $6.6 \pm 1.6$ & $6.2 \pm 1.5$ & $7 \pm 1.6$ & 0.17 \\
\hline night before off-work day & $7.6 \pm 1.1$ & $7.5 \pm 1.4$ & $7.7 \pm 0.9$ & 0.51 \\
\hline Heart rate [beats/min] $(\mathrm{M} \pm \mathrm{SD})$ & $71.8 \pm 10.2$ & $70.3 \pm 11.3$ & $72.8 \pm 9.5$ & 0.48 \\
\hline \multicolumn{5}{|l|}{ Blood pressure $[\mathrm{mm} \mathrm{Hg}](\mathrm{M} \pm \mathrm{SD})$} \\
\hline systolic & $144.3 \pm 12.3$ & $138.7 \pm 11.9$ & $148 \pm 11.4$ & $0.03^{*}$ \\
\hline diastolic & $89.9 \pm 8.9$ & $88.4 \pm 5$ & $90.9 \pm 10.7$ & 0.43 \\
\hline
\end{tabular}

* Statistically significant. 


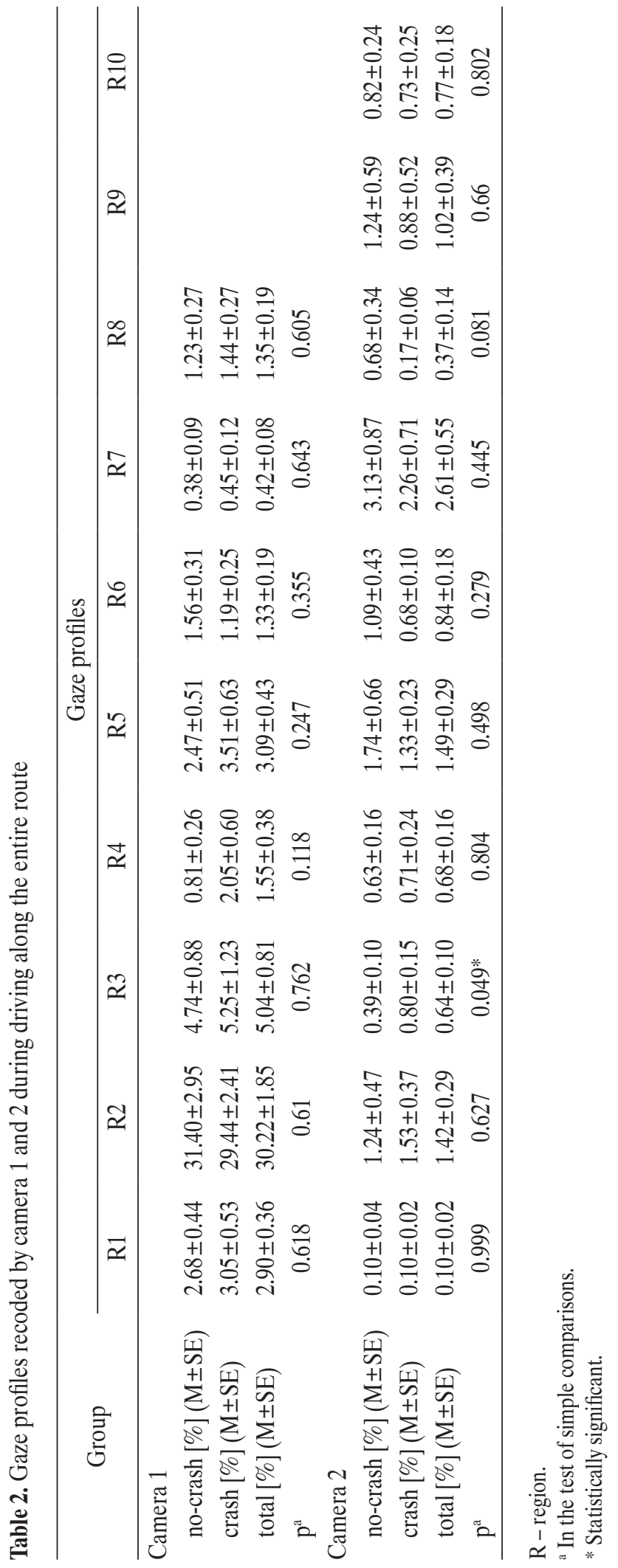

\section{Results of ophthalmological examination}

Results of visual function tests indicated that none of the participants showed abnormalities adversely affecting their driving. In the crash group - 6 drivers (28\%), and in the no-crash group - 8 drivers (33\%) wore glasses. Detailed data and results from the eye examinations will be published in a future manuscript.

\section{Analysis of visual strategy \\ Analysis of visual strategies \\ while driving along the entire route}

The distribution of gaze recorded by camera 1 and 2 in the regions while driving along the entire route are shown in the Table 2. The total percentage of gaze recorded by 2 scene cameras was about $55 \%$. The main reason for this was that each time the driver stopped at the bus stops or a red light, he moves the head out of the visual field of scene cameras. The mean duration of the course was about $33 \mathrm{~min}$, and the mean duration of stop time at each bus stop was $18 \mathrm{~s}(\mathrm{SD}=1.7)$. The driver stopped about 20 times at a red light, the duration of these stops was very disparate (between few seconds and $36 \mathrm{~s}$ ). As shown in the Table 2, participants' visual strategy recorded by camera 1 did not differ between crash and no-crash groups. However, participants' visual strategy recorded by camera 2 was significantly different in region 3 (R3), on which the crash drivers used to fix their gaze significantly more frequently $(p=0.049)($ Table 2$)$.

\section{Visual strategy during collision situation}

Speed before collision and reaction time in the crash and no-crash groups are displayed in the Table 3 . The analysis of covariance indicated that reaction time to possible collision did not differ significantly between the 2 groups, despite different speeds.

The Table 4 shows the gaze in different regions during the $20 \mathrm{~s}$ preceding the collision event for camera 1 . The analysis of visual strategy on the whole group recorded by 
Table 3. Reaction time and speed before collision in the crash and no-crash groups

\begin{tabular}{|c|c|c|c|c|c|}
\hline \multirow{3}{*}{ Variable } & \multicolumn{4}{|c|}{ Reaction time } & \multirow{3}{*}{$\mathrm{p}(0$ vs. 1$)$} \\
\hline & \multicolumn{2}{|c|}{$\begin{array}{c}\text { no-crash }(0) \\
(\mathrm{N}=14)\end{array}$} & \multicolumn{2}{|c|}{$\begin{array}{l}\operatorname{crash}(1) \\
(\mathrm{N}=21)\end{array}$} & \\
\hline & $\mathrm{M}$ & SD & $\mathrm{M}$ & SD & \\
\hline Speed before collision $[\mathrm{km} / \mathrm{h}]$ & 25.7 & 6.4 & 30.3 & 3.5 & 0.023 \\
\hline Time to collision [s] & 2.06 & 2.28 & 2.91 & 3.82 & 0.415 \\
\hline
\end{tabular}

camera 1 showed that participants fixed their gaze mostly in regions 2, 5 and 6. A significant difference was noted in region 6, upon which no-crash drivers fixed their gaze more often $(p=0.016)$. It is presented in the Figure 6.

The Table 4 also shows the gaze in different regions during the $20 \mathrm{~s}$ preceding the collision event for camera 2. The analysis of covariance indicated that systolic blood pressure influenced significantly on gaze recorded by camera 2; thus, the results of gaze adjusted by this covariate are shown in the Table 4 . The analysis of visual strategy on the whole group recorded by camera 2 showed that participants fixed their gaze mostly in regions 6,5 and 9. The no-crash group participants fixed their gaze significantly more often in region $6(\mathrm{p}=0.006)$ and region 10 $(p=0.001)$. It is shown in the Figure 7.

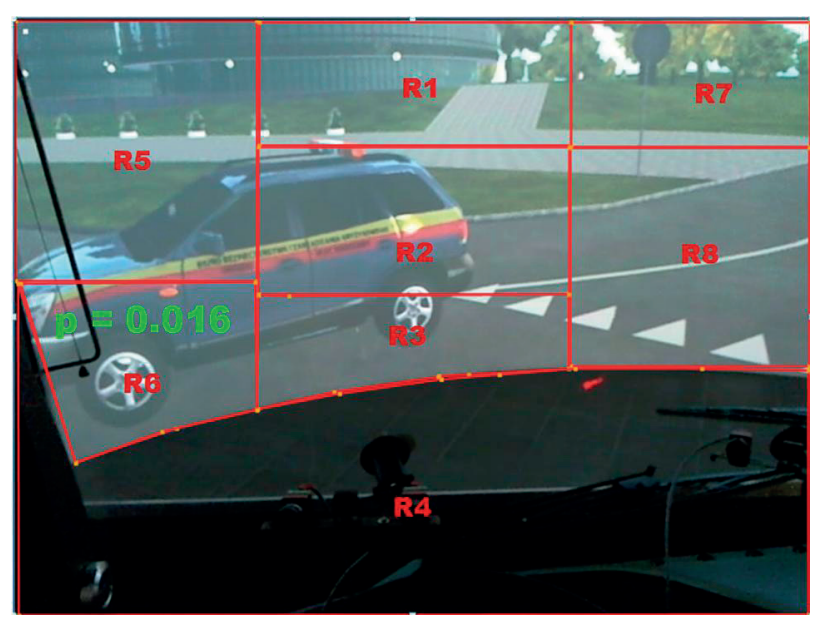

Figure 6. Visual strategy of driving (camera 1) during the $20 \mathrm{~s}$ preceding the collision (significant difference between no-crash vs. crash group)

\section{DISCUSSION}

In the current study, the crash and no-crash groups were compared to select the factors that could potentially affect different visual strategies of drivers. These groups did not differ significantly in age, seniority, sleep duration on the nights before the on-work and the off-work days, BMI, tobacco use, alcohol consumption, heart rate, and resting diastolic blood pressure. The groups differed only in resting systolic blood pressure.

The current study did not find a relationship between age and inclusion in the crash group as found by other authors $[9,19,20]$. In the crash and no-crash groups, the average age and the distribution of age did not differ significantly. No age-related differences may be due to the age range of the examined drivers (31-59 years), which corresponds to the period of good psycho-physiological abilities. Moreover, the average length of employment as a bus

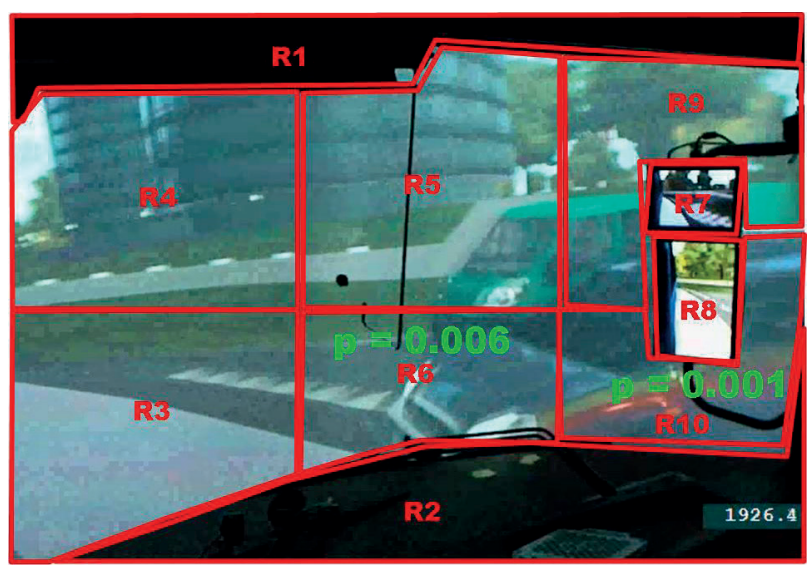

Figure 7. Visual strategy of driving (camera 2) during the 20 $\mathrm{s}$ preceding the collision (significant differences between nocrash vs. crash groups) 


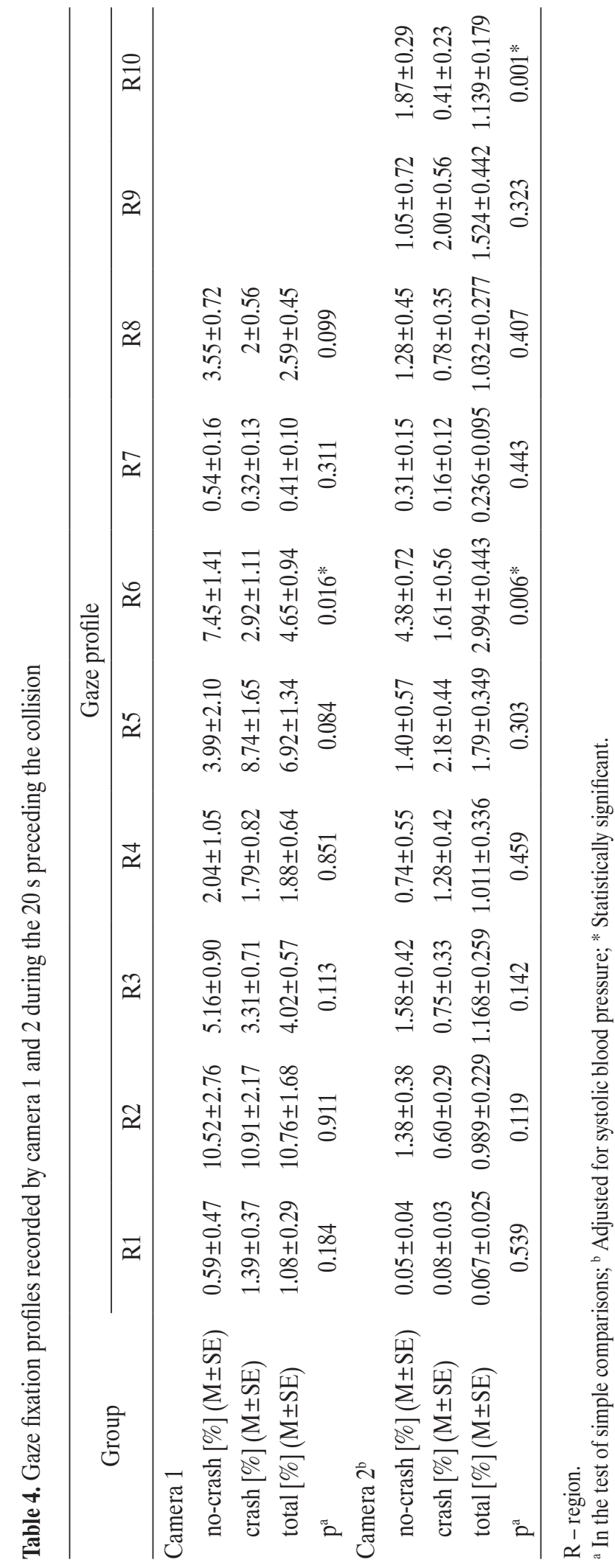

driver was high in both groups (23.1 years in the no-crash group and 22.3 years in the crash group), which connects with great experience in driving. This might compensate for the potential impact of age on the quality of driving. The results seem to concur with the results of Roge et al. [43]. They found that the reduction of the useful visual field, estimated using a target-localization task, was related to the individual's ability to manage the simulated driving situation. In their study, unlike the current study, the ability to process peripheral signals and simulated driving performance deteriorated with increasing age of the participants [43].

As the groups differed in resting systolic blood pressure, it was included in the analysis of covariance. It was found that, after adjusting for this factor, both groups fixed gaze mainly straight-ahead (region 2 in camera 1). Results of the analysis of visual strategies while driving the entire route were consistent with the data from the literature, which showed the driver of a vehicle looks mostly at the road ahead [7,26]. Gaze difference in the visual strategy between the crash and the no-crash drivers was statistically significant in the region 6 $(\mathrm{p}=0.006)$ and region $10(\mathrm{p}=0.001)$ in camera 2 . The participants in the study looked most frequently at the area of the right mirror (region 7, camera 2), due to the necessity of observing people getting in and out of the bus.

These differences may result from the asymmetry of visual perception in the functional field-of-view. Seya et al. studied the response time in the functional field-of-view and eye movements during a simulated car driving [44]. They measured the time required to recognize letters located in different functional areas of the field-of-view. The authors concluded the driver's reaction time was longer for the portion of the field-of-view located to the left of the driver. This confirms our results concerning a bit shorter reaction time in no-crash group, who fixed their gaze in region 6 (low, right corner of the vision field).

The conspicuity of objects on the road, the most important source of information enabling tracking of the moving car, includes moving elements located in the field-of-view. Obser- 
vation of those elements provides information that helps the driver assess the situation and ensure smooth navigation [7]. The possibility of consciously noticing an object while driving (conspicuity) is very important for driving performance. Results suggest that participants in the crash group had more difficulty noticing a dangerous object than participants in the nocrash group. This was likely due to the fact that drivers from the crash group fixed their gaze significantly less in the right lower field-of-view (where the car appeared that did not respect the right of way). These results could be used for developing driver training, based on the direct analysis of visual strategies during simulated driving in order to develop the proper habits of observation of the road and hazard perception.

The results obtained by Vlakveld et al. [45] seem to confirm this suggestion. The authors compared the conspicuity, or ability to note crash situation, between 2 groups of young drivers - the group trained in the RATP program (Régie Autonome de Transport Parisien - Self Governance Paris Transport) and a control group. Conspicuity of the possible collision was significantly higher in the RATP trained group [45]. Similar results were obtained by Pradhan et al. using the RATP training program [46].

Results of the analysis of the visual strategy during the $20 \mathrm{~s}$ prior to the crash indicated that the no-crash participants controlled peripheral field-of-vision (region 6 in camera 1 and region 10 in camera 2) significantly more than the crash drivers. These regions were most important in the visual strategy of drivers which enabled them to avoid the crash.

At the current stage of the study, no generalization of the findings is possible as the study was conducted in only one highly specific traffic situation (simulated collision on roundabout). It is necessary to analyze some other traffic situations before one can make more definite conclusions.

\section{Limitations of the study}

One limitation in the study was the lack of registration of the entire field-of-vision. This was due to the method used for assessing the visual strategy. The eye-tracking device did not contact the participant; thus, the consequence was a loss of a part of the visual field. Special glasses are often used in visual strategy examinations, although they give the opportunity to register the entire field-of-view, but might be poorly tolerated by some participants. This method, despite the limitations, does not interfere with the natural reaction of the driver.

The next limitation is using a driving simulator as a research tool (not testing in a real environment), which could affect the driver's reaction including symptoms of simulator sickness.

\section{CONCLUSIONS}

The results from this study add to a growing literature on the impact of visual strategy on driving performance. In our study, visual strategies of drivers who caused the crash differ significantly from the strategies of drivers who escaped it. These results confirm the usefulness of the method of eye-tracking examination of visual strategy of drivers in collision situations. The method used proved to be suitable for achieving the aim.

Although this method may be used in real conditions, it is difficult to capture the moment of collision because you never know when it will occur. It would be necessary to perform multi-day registration, with no guarantee that at this time the accident occurs. The use of a driving simulator allows for the creation of any planned collision situation and examination of a larger group using the same scenario. The results of our study justify the need for its continuation to be able to identify the most effective visual strategy, with a view to improve the safety of driving.

\section{Practical applications}

Comparison of visual strategies of the drivers who caused the crash and the drivers who escaped it has shown significant differences. These results may be used in the process of driver training, paying particular attention to the glance monitoring, especially at critical points such as crossroads. 


\section{REFERENCES}

1. Tse J, Flin R, Mearns K. Bus driver well-being review: 50 years of research. Transp Res Part F Traffic Psychol Behav. 2006;9(2):89-114, https://doi.org/10.1016/j.trf.2005.10.002.

2. Hanessy DA, Wiesenthal DL, Kohn PM. The influence of traffic congestion, daily hassles, and trait stress susceptibility on state driver stress: An interactive perspective. J Appl Biobehav Res. 2000;5(2):162-79, https://doi.org/10.1111/ j.1751-9861.2000.tb00072.x.

3. Chen C, Xie Y. Modeling the safety impacts of driving hours and rest breaks on truck drivers considering time-dependent covariates. J Safety Res. 2014;51:57-63, https://doi. org/10.1016/j.jsr.2014.09.006.

4. Symon E. [Report of police headquarters on traffic accidents in Poland in 2014]. Warszawa: Komenda Główna Policji, Biuro Prewencji i Ruchu Drogowego, Wydział Ruchu Drogowego ITS; 2014. Polish.

5. Hassan MN, Hawas YE, Maraqa MA. A holistic approach for assessing traffic safety in the United Arab Emirates. Accid Anal Prev. 2012;45:554-64, https://doi.org/10.1016/j.aap. 2011.09.009.

6. Dingus TA, Klauer SG, Neale VL, Petersen A, Lee SE, Sudweeks J, et al. The 100-Car Naturalistic Driving Study. Phase II - Results of the 100-car field experiment. Washington: National Highway Traffic Safety Administration; 2006. Report No.: DOT HS 810593.

7. Kapitaniak B, Walczak M, Kosobudzki M, Jóźwiak Z, Bortkiewicz A. Application of eye-tracking in the testing of drivers - A review of research. Int J Occup Med Environ Health. 2015;28(6):941-54, https://doi.org/10.13075/ijomeh.1896.00317.

8. Treat JR, Tumbas NS, McDonald ST, Shinar D, Hume RD, Mayer RE, et al. Tri-level study of the causes of traffic accidents: Final Report Volume I: Causal factor tabulations and assessments. Institute for Research in Public Safety, Indiana University; 1979. Report No.: DOT HS-805 085.

9. Owsley C. Vision and driving in the elderly. Optom Vis Sci. 1994;71(12):727-35, https://doi.org/10.1097/00006324-19941 2000-00002.
10. Huestegge L, Skottke E, Anders S, Müsseler J, Debus G. The development of hazard perception: Dissociation of visual orientation and hazard processing. Transp Res Part F Traffic Psychol Behav. 2010;13(1):1-8, https://doi.org/10.1016/j.trf. 2009.09.005.

11. Scialfa CT, Pereverseff RS, Borkenhagen D. Short-term reliability of a brief hazard perception test. Accid Anal Prev. 2014;73:41-6, http://dx.doi.org/10.1016/j.aap.2014.08.007.

12. Whelan M, Groeger J, Senserrick T, Triggs T. Alternative methods of measuring hazard perception: Sensitivity to driving experience. RS2002 Road Safety Research, Policing and Education Conference. (CD-ROM) Adelaide, South Australia: Causal Productions.

13. Fisher DL, Pollatsek AP, Pradhan A. Can novice drivers be trained to scan for information that will reduce their likelihood of a crash? Inj Prev. 2006;12(Suppl I):i25-9, https://doi. org/10.1136/ip.2006.012021.

14. Horswill MS, Kemala CN, Wetton M, Scialfa CT, Pachana NA. Improving older drivers' hazard perception ability. Psychol Aging. 2010;25(2):464-9, https://doi.org/10.1037/ a0017306.

15. Scialfa CT, Deschênes MC, Ference J, Boone J, Horswill MS, Wetton M. A hazard perception test for novice drivers. Accid Anal Prev. 2011;43:204-8, https://doi.org/10.1016/j.aap. 2010.08.010.

16. Shahar A, Alberti C, Clarke D, Crundall D. Hazard perception as a function of target location and the field of view. Accid Anal Prev. 2010;42(6):1577-84.

17. Scialfa CT, Borkenhagen D, Lyon J, Deschênes M, Horswill M, Wetton MA. The effects of driving experience on responses to a static hazard perception test. Accid Anal Prev. 2012;45:547-53, https://doi.org/10.1016/j.aap. 2011.09.005.

18. Wetton MA, Horswill MS, Hatherly C, Wood JM, Pachana NA, Anstey KJ. The development and validation of 2 complementary measures of drivers' hazard perception ability. Accid Anal Prev. 2010;42(4):1232-9, https://doi. org/10.1016/j.aap.2010.01.017. 
19. Wetton MA, Horswill MS, Mayhew DR, Simpson HM, Wood KM, Lonero L, et al. On-road and simulated driving: Concurrent and discriminant validation. J Safety Res. 2011;42(4):267-75, https://doi.org/10.1016/j.jsr.2011.06.004.

20. Wetton MA, Hill A, Horswill MS. The development and validation of a hazard perception test for use in driver licensing. Accid Anal Prev. 2011;43(5):1759-70, https://doi. org/10.1016/j.aap.2011.04.007.

21. McDonald CC, Kandadai V, Loeb H, Seacrist TS, Lee YC, Winston Z, et al. Simulated Driving Assessment (SDA) for teen drivers: Results from a validation study. Inj Prev. 2015;21(3):145-52, https://doi.org/10.1136/injuryprev2014-041480.

22. Borowsky A, Horrey WJ, Liang Y, Garabet A, Simmons L, Fisher DL. The effects of momentary visual disruption on hazard anticipation and awareness in driving. Traffic Inj Prev. 2015;16(2):133-9, https://doi.org/10.1080/15389588.20 14.909593.

23. Cyr AA, Stinchcombe A, Gagnon S, Marshall S, Hing MM, Finestone H. Driving difficulties of brain-injured drivers in reaction to high-crash-risk simulated road events: A question of impaired divided attention? J Clin Exp Neuropsychol. 2009;31(4):472-82, https://doi.org/10.1080/138033908 02255627.

24. Klauer SG, Dingus TA, Neale VL, Sudweeks J, Ramsey DJ. The impact of driver inattention on near-crash/crash risk: An analysis using the 100-car naturalistic driving study data [Internet]. Performing Organization Report No. 10. Virginia Tech Transportation Institute; 2006 [cited 2017 Nov 5]. Available from: https://vtechworks.lib.vt.edu/bitstream/handle/10919/55090/DriverInattention.pdf.

25. Liang Y, Lee JD. Combining cognitive and visual distraction: Less than the sum of its parts. Accid Anal Prev. 2010;42(3):881-90, https://doi.org/10.1016/j.aap.2009. 05.001 .

26. Chapman PR, Underwood G. Visual search of dynamic scenes: Event types and the role of experience in viewing driving situations. In: Underwood G, editor. Eye guidance in reading and scene perception. Oxford: Elsevier; 1998. p. 369-94, https://doi.org/10.1016/B978-008043361-5/50018-3.

27. Prado Vega R, van Leeuwen PM, Rendón Vélez E, Lemij HG, de Winter JC. Obstacle avoidance, visual detection performance, and eye-scanning behavior of glaucoma patients in a driving simulator: A preliminary study. PLoS One. 2013;8:e77294, https://doi.org/10.1371/journal.pone. 0077294.

28. Taylor T, Pradhan, AK, Divekar G, Romoser M, Muttart J, Gomez J, et al. The view from the road: The contribution of on-road glance-monitoring technologies to understanding driver behaviour. Accid Anal Prev. 2013;58:175-86, https:// doi.org/10.1016/j.aap.2013.02.008.

29. Fildes B, Charlton J, Muir C, Koppel S. Driving responses of older and younger drivers in a driving simulator. Annu Proc Assoc Adv Automot Med. 2007;51:559-72.

30. Shin D, Sakai H, Uchiyama Y. Slow eye movement detection can prevent sleep-related accidents effectively in a simulated driving task. J Sleep Res. 2011;20(3):416-24, https://doi. org/10.1111/j.1365-2869.2010.00891.x.

31. Urwyler P, Gruber N, Müri RM, Jäger M, Bieri R, Nyffeler T, et al. Age-dependent visual exploration during simulated day- and night driving on a motorway: A cross-sectional study. BMC Geriatr. 2015;15:18, https://doi.org/10.1186/ s12877-015-0015-2.

32. Brown T, He Y, Roe C, Schnell T. Is more better? Night vision enhancement system's pedestrian warning modes and older drivers. Ann Adv Automot Med. 2010;54: $343-50$.

33. Sandberg D, Anund A, Fors C, Kecklund G, Karlsson JG, Wahde M, et al. The characteristics of sleepiness during real driving at night - A study of driving performance. Physiology and subjective experience. Sleep. 2011;34(10):1317-25, https://doi.org/10.5665/SLEEP.1270.

34. Johnson L, Sullivan B, Hayhoe M, Ballard D. Predicting human visuomotor behaviour in a driving task. Philos Trans $\mathrm{R}$ Soc Lond B Biol Sci. 2014;369(1636):20130044, https://doi. org/10.1098/rstb.2013.0044. 
35. Kandil FI, Rotter A, Lappe M. Car drivers attend to different gaze targets when negotiating closed vs. open bends. J Vis. 2010;10(4):24.1-11, http://journalofvision.org/10/4/24/.

36. Lappi O. Future path and tangent point models in the visual control of locomotion in curve driving. J Vis. 2014;14(12):21.1-22, https://doi.org/10.1167/14.12.21.

37. Ni R, Kang JJ, Andersen GJ. Age-related declines in car following performance under simulated fog conditions. Accid Anal Prev. 2011;42(3):818-26, https://doi.org/10.1016/ j.aap.2009.04.023.

38. Stavrinos D, Jones JL, Garner AA, Griffin R, Franklin CA, Ball D, et al. Impact of distracted driving on safety and traffic flow. Accid Anal Prev. 2013;61:63-70, https://doi.org/ 10.1016/j.aap.2013.02.003.

39. Mayhew DR, Simpson HM, Wood KM, Lonero L, Clinton KM, Johnson AG. On-road and simulated driving: Concurrent and discriminant validation. J Safety Res. 2011;42(4):267-75, https://doi.org/10.1016/j.jsr.2011.06.004.

40. Sińczuk-Walczak H, Siedlecka J, Szymczak W, Gadzicka E, Walczak A, Kowalczyk G, et al. [Neurological symptoms and syndromes in municipal transport drivers]. Med Pr. 2015;66(3): 333-41, https://doi.org/10.13075/mp.5893.00208. Polish.

41. Headache Classification Committee of the International Headache Society (IHS). The International Classification of
Headache Disorders. 3rd edition (beta version). Cephalalgia. 2013;33(9):629-808, https://doi.org/10.1177/033310241 3485658.

42. Rayner K. Eye movements in reading and information processing: 20 years of research. Psychol Bull. 1998;124(3):372422, https://doi.org/10.1037/0033-2909.124.3.372.

43. Rogé JL, Pébayle T, Campagne A, Muzet A. Useful visual field reduction as a function of age and risk of accident in simulated car driving. Invest Ophthalmol Vis Sci. 2005;46(5):1774-9, https://doi.org/10.1167/iovs.04-0540.

44. Seya Y, Nakayasu H, Yagi T. Useful field of view in simulated driving: Reaction times and eye movements of drivers. Iperception. 2013;4(4):285-98, https://doi.org/10.1068/ $\mathrm{i} 0512$.

45. Vlakveld W, Romoser MRE, Mehranian H, Diete F, Pollatsek A, Fisher DL. Do crashes and near crashes in simulatorbased training enhance novice drivers' visual search for latent hazards? Transp Res Rec. 2011;2265:153-60, https://doi. org/10.3141/2265-17.

46. Pradhan AK, Pollatsek A, Knodler M, Fisher DL. Can younger drivers be trained to scan for information that will reduce their risk in roadway traffic scenarios that are hard to identify as hazardous? Ergonomics. 2009;52(6):657-73, https://doi.org/10.1080/00140130802550232.

This work is available in Open Access model and licensed under a Creative Commons Attribution-NonCommercial 3.0 Poland License - http://creativecommons.org/ licenses/by-nc/3.0/pl/deed.en. 